\title{
VERIFIKASI AKUN DATABASE DENGAN PENERAPAN METODE TEMPLATE MATCHING PADA KARATERISTIK WAJAH PERSONAL
}

\author{
Ginting Pebrindanov ${ }^{1}$ \\ danov.moch@gmail.com
}

\author{
Widi Hapsari ${ }^{2}$ \\ widi@ukdw.ac.id
}

\author{
Yuan Lukito $^{3}$ \\ yuanlukito@ti.ukdw.ac.id
}

\begin{abstract}
The identification of account is a step to keep the important data secure. Nowadays, it can be done by using username and password, but, after see the reality, the using of username and password can't keep the data secure from the thief. Because of that, the verification of the characteristic of personal face can be a solution to change the using username and password. The method that can be used for verification is template matching.It is implemented in four features of personal face, such as left eye, right eye, nose and lips. The four images of each feature will be extracted with wavelet haar method. The feature extraction will be done during template taking process and verification. The result of this research, the result of verification is determined by two factors, such as the distance between face and web camera is different when the template taking process and the verification process and the diferrent brightness condition when the template taking process and the verification proccess. The threshold value that has been decided is not really able to block the unregistered data. Then the accuracy of the verification activity is still low and it is still not able yet to identify an account well.
\end{abstract}

Keywords : template matching, four features of personal face, wavelet haar, feature extraction, template taking proccess, verification, euclidean distance, threshold value

\section{Pendahuluan}

Identifikasi sebuah identitas dengan sebuah gambar adalah salah satu metode yang dapat digunakan sebagai ganti password agar dapat $\log$ in ke dalam sebuah sistem dikarenakan sudah banyak terjadi pencurian data melalui akun personal, berupa username dan password. Metode template matching adalah salah satu metode sederhana yang dapat digunakan untuk identifikasi sebuah akun agar sebuah akun dapat diverifikasi dan kemudian dapat masuk ke dalam sistem.

\section{Landasan Teori}

\subsection{Pengolahan Citra Digital (Digital Image Processing)}

Pengolahan Citra Digital adalah pengaplikasian sejumlah algoritma untuk memproses sebuah input yang berupa citra menjadi hasilnya juga berupa citra.

\subsection{Citra Digital}

Citra digital adalah susunan dari beberapa elemen yang berada pada lokasi tertentu dan memiliki nilai yang disebut dengan pixel.

\footnotetext{
${ }^{1}$ Program Studi Teknik Informatika, Fakultas Teknologi Informasi, Universitas Kristen Duta Wacana.

${ }^{2}$ Program Studi Teknik Informatika, Fakultas Teknologi Informasi, Universitas Kristen Duta Wacana.

${ }^{3}$ Program Studi Teknik Informatika, Fakultas Teknologi Informasi, Universitas Kristen Duta Wacana.
} 


\subsection{Pixel}

Pixel adalah koordinat spasial yang mendeskripsikan tentang posisi sebuah titik dalam suatu citra beserta nilai intesitasnya.

\subsection{Warna Tingkat Keabuan (grayscale)}

Warna tingkat keabuan (grayscale) adalah suatu proses merubah citra berwarna menjadi citra grayscale dengan menggunakan persamaan rumus [1].

$$
s=\frac{r+g+b}{3}
$$

\subsection{Akuisisi Citra}

Akuisisi Citra adalah tahap awal untuk mendapatkan sebuah citra digital dengan tujuan untuk menentukan data yang diperlukan dan memilih metode perekaman citra digital.

\subsection{Pengambangan (Thresholding)}

Pengambangan (Thresholding) adalah proses merubah sebuah citra menjadi citra biner, yakni citra yang memiliki dua nilai tingkat keabuan, yakni hitam dan putih. Pengambangan terbagi atas dua jenis, yakni pengambangan global dan pengambangan lokal adaptif.

\subsection{Ekstraksi Ciri} diamati.

Ekstraksi Ciri adalah proses mengambil ciri - ciri tertentu dari karakter yang

\subsection{Wavelet Haar}

Wavelet Haar adalah proses untuk ekstraksi ciri terhadap suatu citra, yang hasilnya akan terbagi menjadi empat komponen, yakni LL, HL, LH dan HH. LL adalah komponen approksimasi yang lebih mirip dan merupakan versi halus dari citra aslinya. HL adalah komponen detil vertikal yang menunjukkan citra tepi dalam arah vertikal. LH adalah komponen citra horisontal yang menunjukkan citra tepi dalam arah horisontal. HH adalah komponen detil diagonal yang menunjukkan citra tepi dalam arah diagonal.

\subsection{Pengenalan}

Pengenalan adalah proses untuk mengenali karakter yang diamati dengan membandingkan pada karakter yang ada pada basis data.

\subsection{Template Matching}

Template Matching adalah proses untuk mencari lokasi template yang sesuai di dalam sebuah gambar yang besar. Penerapannya dapat dilakukan dengan menghitung nilai euclidean distance antara ciri objek yang diamati dengan ciri template yang tersedia.

\subsection{Euclidean Distance}

Euclidean Distance adalah metode untuk menghitung jarak dari suatu data terhadap sekelompok data. Jika nilai euclidean distance mendekati nol, maka data tersebut dapat dikatakan mirip dengan data yang ada pada kumpulan data tersebut. Persamaan dari euclidean distance adalah sebagai berikut.

$$
d_{i j}=\sqrt{\sum_{k=1}^{n}\left(X_{i k}-X_{j k}\right)^{2}}
$$




\section{Perancangan Sistem}

\subsection{Flow Chart Pengambilan Template dan Verifikasi}

Sistem secara umun akan mengakuisisi citra wajah dan kemudian mengambil ciricirinya untuk kemudian diekstraksi dan disimpan ke dalam basis data agar dapat dijadikan template untuk dibandingkan dengan data uji pada waktu proses verifikasi. Berikut ada dua flow chart yang dapat mendeskripsikan cara kerja sistem, yakni flow chart pengambilan template dan flow chart verifikasi.

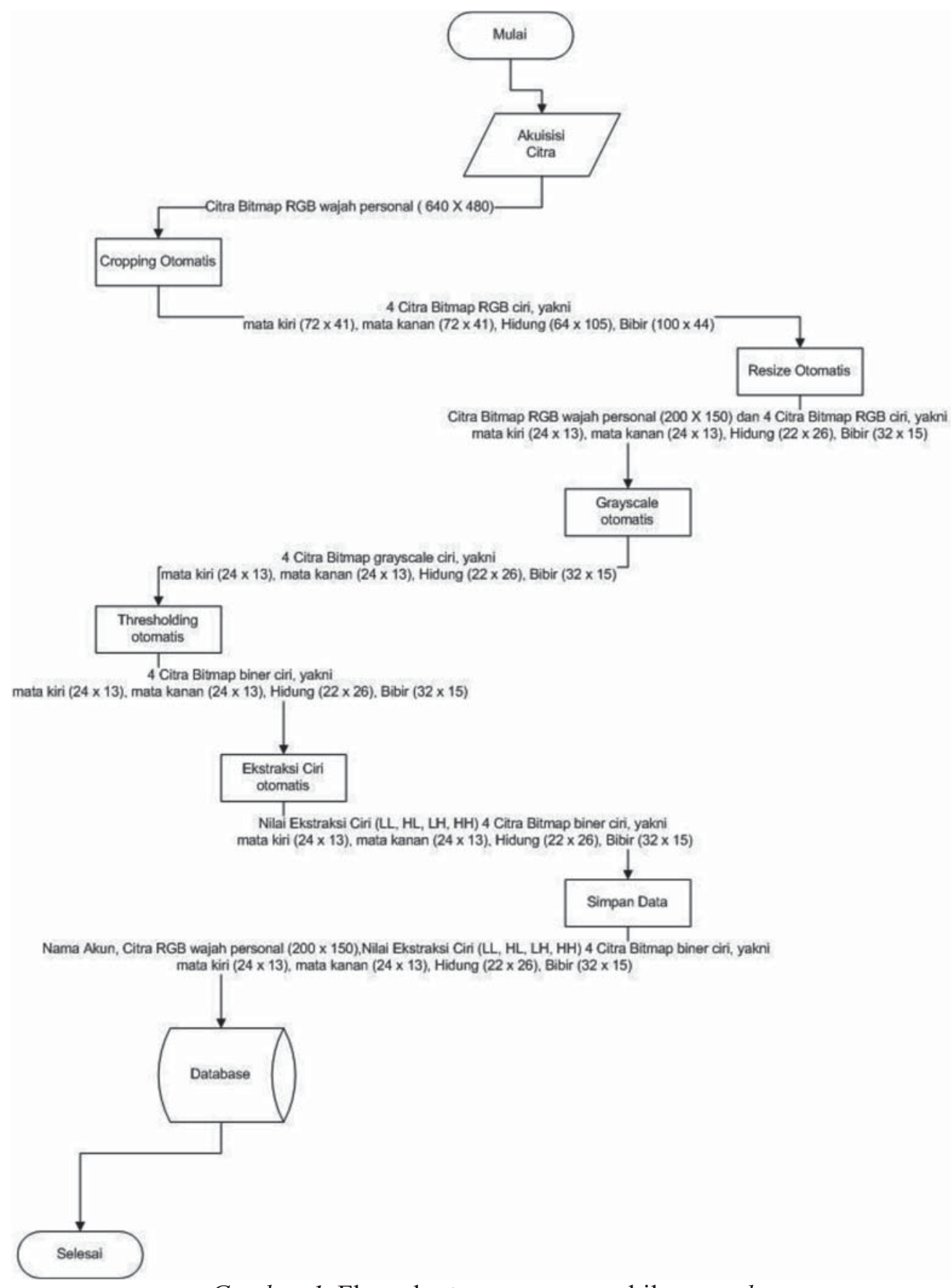

Gambar 1. Flow chart proses pengambilan template 


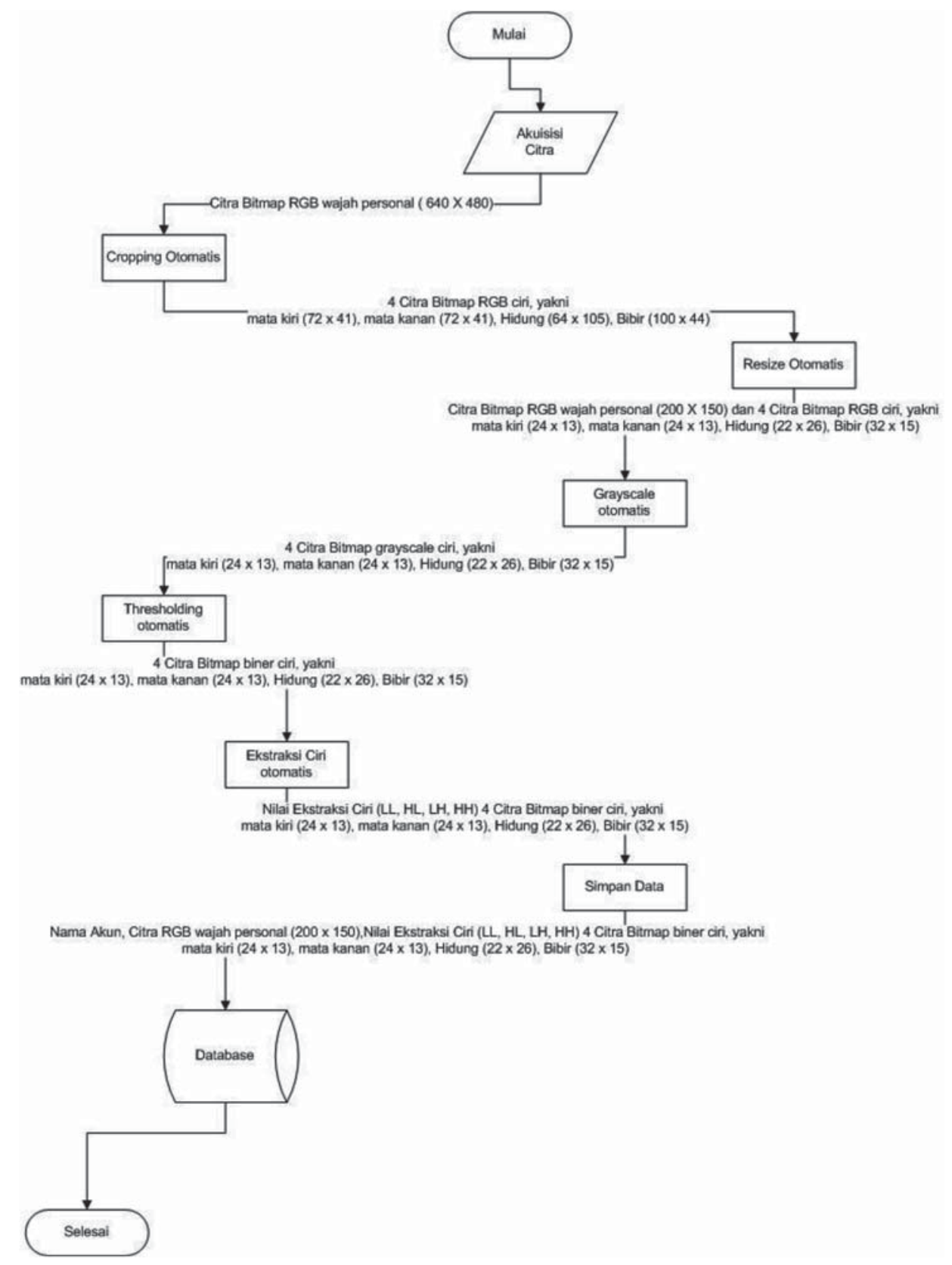

Gambar 2. Flow chart proses verifikasi

\subsection{Penjelasan Proses}

Berikut adalah penjelasan dari beberapa proses dari cara kerja sistem yang dijabarkan pada kedua flow chart di atas, yakni pada Gambar 1 dan Gambar 2

1. Mulai. Sistem mulai bekerja.

2. Akuisisi Citra. Sistem akan mengambil gambar melalui web camera.

3. Cropping Otomatis. Sistem akan melakukan cropping otomatis untuk mendapatkan empat citra bitmap ciri yang diperlukan, yakni mata kiri, mata kanan, hidung dan bibir sesuai dengan proporsi lokasi yang ditentukan.

4. Resize Otomatis. Sistem akan melakukan resize otomatis untuk merubah ukuran dari empat citra bitmap ciri yang diperlukan dan yang telah diperoleh sebelumnya melalui proses cropping otomatis, yakni mata kiri, mata kanan, hidung dan bibir.

5. Grayscale otomatis. Ini adalah proses untuk merubah citra RGB dari empat ciri, yakni mata kiri, mata kanan, hidung dan bibir yang telah diubah ukurannya secara otomatis melalui proses resize otomatis menjadi citra grayscale atau keabu - abuan. 
6. Thresholding otomatis. Ini adalah proses untuk merubah citra grayscale dari empat ciri, yakni mata kiri, mata kanan, hidung dan bibir menjadi citra biner, yaitu citra yang terdiri atas dua warna, yaitu hitam dan putih, yang nilainya hanya 0 dan 255 .

7. Ekstraksi Ciri otomatis. Ini adalah proses untuk mengambil nilai ciri dari empat bitmap ciri yang telah diperoleh dan telah dirubah menjadi citra biner.

8. Simpan data. Ini adalah proses untuk menyimpan seluruh data yang diperlukan, yang nantinya data - data ini akan dijadikan sebagai template untuk kemudian diuji dengan data uji pada waktu verifikasi ke dalam sebuah basis data.

9. Database. Seluruh data yang disimpan melalui proses simpan data akan tersimpan di dalam basis data atau database.

10. Verifikasi. Ini adalah proses untuk menguji apakah sistem dapat mengidentifikasi sebuah akun dengan akurat.

11. Tampilkan hasil. Ini adalah proses untuk menampilkan hasil verifikasi.

12. Selesai. Proses pengambilan data maupun verifikasi telah selesai dilakukan.

\subsection{Rancangan Pengujian}

Berikut adalah rancangan pengujian yang akan dilakukan terhadap sistem.

1. Pengujian dari sistem akan dilakukan terhadap 36 orang, dengan kriteria 30 orang didaftar menjadi template dan 6 orang menjadi data uji

2. Untuk proses pengambilan template dan verifikasi, akuisisi citra dilakukan sebanyak 5 kali.

3. Proses pengambilan foto tersebut akan menggunakan web camera.

4. Jarak yang digunakan untuk pengambilan gambar antara wajah dengan layar laptop adalah sekitar $30-40 \mathrm{~cm}$ dan dilakukan di ruangan berlatar belakang cerah dengan penerangan yang bersumber dari lampu neon maupun cahaya matahari.

5. Pengujian hanya akan dilakukan terhadap wajah personal yang tidak memakai atribut apapun, seperti kacamata dan cadar serta hanya terfokus pada empat ciri dari wajah saja, yakni bentuk mata kiri, bentuk mata kanan, hidung dan bibir.

6. Penentuan hasil verifikasi akan mengacu pada nilai terkecil dari total euclidean distance dari keempat ciri yang telah ditentukan.

7. Penolakan terhadap sebuah akun asing akan mengacu pada proses perbandingan antara total euclidean distance dengan nilai threshold yang telah ditentukan.

8. Pengukuran tingkat akurasi dari sistem menggunakan metode confusion matrix.

\section{Hasil Dan Pembahasan}

\subsection{Analisis Sistem}

Kemampuan sistem dalam melakukan set up template dan juga verifikasi sangat bergantung pada dua hal berikut, yakni

1. Kondisi pencahayaan pada waktu proses akuisisi citra. Apabila kondisi pencahayaan pada waktu verifikasi berbeda sangat jauh dengan pada waktu pengambilan template, maka akan mempengaruhi hasil verifikasi yang akan diperoleh.

2. Jarak antara muka dengan web camera. Apabila, jarak antara muka dengan web camera pada waktu proses akuisisi citra untuk verifikasi berbeda dengan pengambilan template, maka hasil verifikasi yang akan diperoleh bisa berbeda.

\subsection{Uji Coba Sistem}

Berdasarkan hasil dari pengujian terhadap 36 sampel, akhirnya diperoleh tingkat akurasi sebesar 67,22 \%. Threshold untuk euclidean distance yang digunakan untuk 
menolak sebuah akun asing yang tidak terdaftar sebagai template adalah 11. Jadi, apabila nilai euclidean distance yang dihasilkan setelah dibagi dengan 1.000.000, berada dibawah nilai threshold, maka data tersebut berhasil diverifikasi, tetapi jika tidak maka, data tidak dapat diverifikasi. Alasan nilai euclidean distance yang dihasilkan harus dibagi dengan 1.000.000 adalah agar nilai euclidean distance menjadi lebih sederhana karena nilai euclidean distance yang dihasilkan berada pada skala jutaan. Rumus yang digunakan untuk menghitung tingkat akurasi dapat dilihat pada rumus [3].

Tingkat akurasi $=\frac{\text { jumlah sampel yang dikenali dengan benar }}{\text { jumlah sampel keseluruhan }} \times 100 \%$

\section{Kesimpulan} berikut

Berdasarkan hasil penelitian tersebut, diperoleh beberapa kesimpulan sebagai

1. Proses verifikasi yang dilakukan oleh sistem itu hanya kepada empat ciri yang diambil, yakni mata kiri, mata kanan, hidung dan bibir.

2. Pada penerapan metode template matching, hasil verifikasi sangat ditentukan oleh dua hal, yakni jarak antara wajah dengan web camera ketika proses akuisisi citra dan kondisi pencahayaan.

3. Penentuan nilai threshold untuk euclidean distance ternyata masih belum mampu untuk menolak data asing agar tidak dapat diverifikasi.

4. Tingkat akurasi sistem berdasarkan hasil uji coba terhadap 36 sampel dengan 30 diantaranya telah terdaftar sebagai template, adalah $67,22 \%$.

\section{Daftar Pustaka}

Aljarrah, I., Ghorab, S., \& Khater, I. (2012). Object Recognition System Using Template Matching Based On Signature and Principal Component Analysis. International Journal of Digital Information and Wireless Communications , 156 - 163.

Basuki, A., Palandi, J., \& Fatchurrochman. (2005). Pengolahan Citra Digital Menggunakan Visual Basic. Yogyakarta: Graha Ilmu.

Buyung, J., Usman, K., \& Novamizanti, L. (2011). Desain dan Simulasi Sistem Dokumentasi Tugas Akhir Otomatis Menggunakan WebCam Berbasis Image Processing dan K-Nearest Neighbors. Jurusan Teknik Elektro - Institut Teknologi Telkom .

Gonzalez, R., \& Woods, R. (2007). Digital Image Processing Third Edition. Prentice Hall.

Hartanto, S., Sugiharto, A., \& Endah, S. (2012). Optical Character Recognition Menggunakan Algoritma Template Matching Correlation. Journal of Informatics And Technology , I, 11 - 20.

Joshi, K. (2013). A Template Matching and Support Vector Machine Based Approach for Human Eye Localization and Verification. International Journal For Advance Research In Engineering And Technology, I (VI).

Leksono, B., Hidayatno, A., \& Isnanto, R. (2011). Aplikasi Metode Template Matching untuk Klasifikasi Sidik Jari. TRANSMISI , 1 - 6.

Lidya, S. (2012). Implementasi dan Analisis Kinerja Algoritma Arithmetic Coding dan 
Shannon-Fano Pada Kompresi Citra Bmp,(Skripsi S1, Universitas Sumatera Utara,2012),dari http://repository.usu.ac.id/handle/123456789/37738.

Mulyawan, H., Samsono, M., \& Setiawardhana. (2011). Identifikasi Dan Tracking Objek Berbasis Image Processing Secara Real Time. EEPIS Final Project .

Putra, D. (2010). Pengolahan Citra Digital. Yogyakarta: C.V.Andi OFFSET.

Rahman, M., \& Wasista, S. (2010). Sistem Pengenalan Wajah Menggunakan Webcam Untuk Absensi Dengan Metode Template Matching. EEPIS Final Project .

Rijal, Y., \& Ariefianto, R. (2008, Juni 21). Deteksi Wajah Berbasis Segmentasi Model Warna Menggunakan Template Matching Pada Objek Bergerak. Seminar Nasional Aplikasi Teknologi Informasi 2008 (SNATI 2008) .

S.D, Jadhav., A.B, Barbadekar., \& S.P, Patil. (2011). Euclidean Distance Based Fingerprint Matching. NEHIPISIC'11 Proceeding of 10th WSEAS international conference on electronics, hardware, wireless and optical communications, Pages $148-153$.

Santi, C. (2011). Mengubah Citra Berwarna Menjadi GrayScale dan Citra Biner. Jurnal Teknologi Informasi Dinamik, 16.

Shih, F. (2010). Image Processing And Pattern Recognition Fundamentals And Techniques. New Jersey: John Wiley \& Sons, Inc., Hoboken.

Zhou, H., Wu, J., \& Zhang, J. (2010). Digital Image Processing Part I. Bookboon. 